\title{
APLICAÇÃO DAS DIMENSÕES CULTURAIS DO PROJETO GLOBE NA AVALIAÇÃO DA LIDERANÇA ÉTICA: UM ESTUDO INTERCULTURAL EM PORTUGAL E GUINÉ-BISSAU
}

\author{
APPLICATION OF PROJECT GLOBE'S CULTURAL DIMENSIONS IN \\ EVALUATING ETHICAL LEADERSHIP: AN INTERCULTURAL STUDY \\ IN PORTUGAL AND GUINEA BISSAU
}

Data de submissão: 09/02/2014 Aceite: $29 / 09 / 2015$

Manuel Portugal Ferreira ${ }^{1}$ Mamadú Aua Mané Martinho Ribeiro Almeida ${ }^{3}$

\section{RESUMO}

Neste artigo foi avaliado como as características culturais nacionais influenciam as percepções de liderança ética. Metodologicamente, foi realizado um estudo empírico relacionando as nove dimensões culturais do projeto GLOBE - Distância ao poder, Aversão à incerteza, Igualitarismo de gênero, Coletivismo de grupo/coletivismo institucional, Orientação para o desempenho, Orientação para o futuro, Orientação humana e Assertividade - com liderança ética. A amostra consistiu em 216 estudantes de Administração: 138 em Portugal e 78 na Guiné-Bissau As análises, usando um modelo estrutural, visaram identificar diferenças entre os países, observando como cada uma das nove dimensões culturais se associa à percepção de comportamentos de liderança ética. Num contexto mundial, em que surgem diversas referências às práticas éticas das empresas, este estudo contribui para alargar o debate das práticas éticas, além da forma como a liderança é exercida. $O$ estudo contribui para entender melhor como caraterísticas culturais podem promover ou dificultar a liderança ética nas organizações. Adicionalmente, foca em dois países menos estudados, e explora a dimensão de liderança ética, que é ainda incipientemente entendida, mas que pode ter um forte impacto em como as empresas multinacionais organizam as suas atividades no estrangeiro.

Palavras-chave: Liderança ética, Estudo intercultural, Projeto GLOBE, Guiné-Bissau, Portugal

\footnotetext{
1 Possui graduação em Economia pela Universidade de Coimbra, UC, Portugal. Mestrado pela Universidade Católica Portuguesa (Lisboa) e Licenciado em Economia pela Universdade de Coimbra. Doutorado em Business Administration pela David Eccles School of Business da Universidade de Utah, EUA. Pós-doutorando na FEA/USP. Atualmente é professor na Universidade Nove de Julho, no Programa de Mestrado e Doutorado em Administração. Barra Funda. São Paulo. Brasil. E-mail: manuel.portugal.ferreira@gmail.com

2 Possui mestrado em Negócios internacionais no Departamento de Gestão e Economia da ESTG-IPL. E-mail: mamadumane1@hotmail.com 3 Possui graduação em Administração de Empresas pela Fundação Getúlio Vargas - SP, mestrado em Administração pela Universidade de São Paulo e doutorado em Administração pela Universidade de São Paulo. Atualmente é professor associado da Faculdade de Economia, Administração e Contabilidade da Universidade de São Paulo - FEA/USP. São Paulo. Brasil. E-mail: martinho@usp.br
} 


\section{ABSTRACT}

In this article we assess how national cultural characteristics influence the perceptions of ethical leadership. Methodologically, we have conducted an empirical study relating the nine cultural dimensions of Project GLOBE - Power distance, Uncertainty avoidance, Gender egalitarianism, In-group collectivism/Institutional collectivism, Performance orientation, Future orientation, Humane orientation and Assertiveness - with ethical leadership. The sample consisted on 216 management students in Portugal (138) and Guinea Bissau (78). The analyses, using a structural model, sought to identify differences between the countries in how each of the nine cultural dimensions relates to the perception of ethical leadership behaviors. In a worldwide context where multiple concerns emerge pertaining to firms' ethical practices, this study contributes to expand the debate on the ethical practices to the manner in which leadership is exerted. The study contributes to better understand how the cultural characteristics may promote or weaken an ethical leadership in organizations. Moreover, it focuses on two countries that are less often researched and exploring the dimension of ethical leadership that is ill understood but that may bear a substantial impact on how multinational firms organize their foreign activities.

Keywords: Ethical leadership, Intercultural study, Project GLOBE, Guinea-Bissau, Portugal

\section{INTRODUÇÃO}

A recente onda de escândalos corporativos nos EUA, Europa, Sudeste Asiático, Austrália e mesmo na América Latina tem induzido ao maior interesse dos gestores, das agências reguladoras e dos investigadores sobre a temática da ética empresarial (LEWIS, 1985; BROWN; TREVIÑO; HARRISON, 2005). Os escândalos, que nas últimas décadas envolveram empresas como a Parmalat, Enron, WorldCom, Arthur Anderson, entre várias outras, têm consequências negativas para acionistas, trabalhadores, clientes, fornecedores (CACIOPPE et al., 2007) e toda a sociedade. Face ao maior escrutínio público pelas populações e autoridades competentes, as empresas esperam que os seus trabalhadores, independentemente do nível hierárquico e funcional que ocupam, mantenham altos padrões de comportamento ético (LAU et al., 2012).

Assim, diante de problemas com a falta de ética nas práticas empresariais, alguns agentes têm clamado por uma liderança mais ética (FREEMAN; STEWART, 2006). Talvez as pressões sobre os altos executivos - CEOs, Presidentes e equipes da Alta Administração (Top Management Team, na sua designação em inglês) sejam maiores pela convicção, que os gestores e executivos devam dar o exemplo das práticas e comportamentos que são desejados na empresa. Ou seja, uma liderança ética é, assim, entendida como o caminho para uma organização também ser ética (BROWN et al., 2005). Importa, então, focar não apenas o que são os comportamentos éticos e não éticos da liderança, mas também os seus antecedentes e os resultados desses comportamentos (WALUMBWA; SCHAUBROECK, 2009; AVEY et al., 2012).

Neste artigo examina-se especificamente um dos possíveis antecedentes das percepções e comportamentos em matéria de liderança ética: a cultura nacional, que matiza o corpo de normas, valores, atitudes e comportamentos dos indivíduos. Cultura, por outro lado, tem sido apontada como um dos determinantes importantes na tomada de decisão ética (NEJATI et al., 2011). A cultura é todo complexo que inclui conhecimentos, crenças, valores, atitudes, arte, direito, moral, costumes e quaisquer outras capacidades e hábitos adquiridos pelo homem como membro da sociedade (TYLOR, 1871). A cultura representa um sistema de padrões de mecanismos de controle, planos, receitas e instruções para governar o comportamento (GEERTZ, 1989). Uma vez que certos valores, comportamentos éticos ou princípios morais variam de um país para outro, a compreensão da relação entre cultura e ética nos negócios vai permitir às organizações e seus gestores operarem de forma eficaz e eficiente no mercado global e diminuir seu investimento em riscos causados por investimentos em países corruptos (PHAU; KEA, 2007). 
Neste artigo estuda-se como um conjunto selecionado de dimensões culturais podem influenciar as percepções do que são comportamentos de uma liderança ética. Especificamente utilizam-se as oito dimensões culturais do Projeto GLOBE (HOUSE et al., 2004) - Distância ao poder, Aversão à incerteza, Igualitarismo de gênero, Coletivismo de grupo/Coletivismo institucional, Orientação para o desempenho, Orientação para o futuro, Orientação humana e Assertividade - para propor o seu impacto nas percepções do que constitui uma liderança ética. Esta abordagem tem o benefício de aferir as influências dos próprios padrões éticos vigentes em sociedades distintas, a medida que permite diferenciar como em diferentes países, face a um quadro cultural idiossincrático, os indivíduos entendem e percebem a liderança ética.

Metodologicamente realiza-se um estudo empírico, com dados coletados por questionário junto de estudantes de graduação de cursos da área de Administração em Portugal e na Guiné-Bissau. $O$ instrumento conteve os itens do Projeto GLOBE, para a aferição das características culturais, e de Brown et al. (2005) para a percepção de liderança ética. Apesar da partilha de uma herança histórica e uma proximidade cultural, estes dois países tiveram em anos mais recentes trajetórias de desenvolvimento distintas. A Guiné-Bissau é um país africano de colonização portuguesa, finda em 1974, da qual herdou muitas características culturais. Esta herança cultural torna os testes estatísticos mais exigentes, dado que se espera que o legado colonial tenha imbuído particularidades à sociedade e cultura Guineense. No entanto, como a cultura também depende de um conjunto de outros fatores, como o desenvolvimento institucional e econômico, a homogeneidade ou heterogeneidade populacional, etc., talvez os percursos diferentes e a diversidade étnica na Guiné-Bissau contribuam para que algumas diferenças existam. Assim, usando amostras de estudantes destes dois países impõe-se um teste mais exigente às hipóteses, do que quando se usa dois países com traços culturais marcadamente distintos. Também importa notar que a utilização de estudantes como participantes é adequada na medida em que permite começar a entender, e antever, como é que a futura geração de profissionais melhor formados nas Universidades de ambos os países previsivelmente reagirão e se comportarão em matéria de ética, quando deparados com situações de liderança organizacional. As limitações impostas por uma amostra de estudantes são bem conhecidas (ver, por exemplo, LAU et al., 2012) pelo que extensões para outras amostras e domínios exigem a usual cautela.

Os resultados indicaram a existência de algumas diferenças culturais significativas entre os dois grupos de participantes. No entanto, os testes não paramétricos realizados salientam diferenças importantes entre os dois países, realçando a importância de se compreender o que efetivamente determina a percepção de liderança ética, usando dimensões culturais. O estudo contribui conceitualmente para melhor entender as influências de aspectos específicos das culturas nacionais, em especial das culturas dos dois países analisados (Guiné-Bissau e Portugal), sobre as percepções do que constituem comportamentos de liderança ética e da própria construção das características culturais. $O$ estudo contribui para a prática, ao identificar alguns vetores, onde se pode atuar ao nível dos valores mais básicos, que são os valores culturais, para melhorar o desempenho dos líderes organizacionais. Ao usar dois países pouco escrutinados, o estudo contém uma aplicação, que pretende ser inédita, a partir das escalas culturais em dois países relativamente periféricos da geoeconomia mundial. É de salientar que são muito escassos os estudos acadêmicos sobre países da África Subsaariana, e nomeadamente sobre a cultura na Guiné-Bissau. Para pesquisa futura, salienta-se que este estudo analisou o impacto da cultura na percepção do que é uma liderança ética, porém podem antever-se extensões a outras vertentes organizacionais, como as estratégias empresariais e as práticas de gestão de recursos humanos. 


\section{REVISÃO DE LITERATURA}

O estudo da ética é uma tradição antiga, enraizada em crenças religiosas, culturais e filosóficas (LEWIS, 1985). Analisar comportamentos ou percepções de ética envolve, assim, examinar este conjunto amplo de crenças, normas sociais e valores para entender como se aplicam às situações quotidianas, quais os valores que os indivíduos e organizações seguem (ou deviam seguir) nas suas ações e como orientam as suas decisões. A ética prende-se com a conduta humana e, segundo Cacioppe et al. (2007), relaciona-se com a forma como os indivíduos se relacionam entre si e os princípios que regem essas interações entre as pessoas, inclusive em contexto profissional (VICTOR; CULLEN, 1988). Bondarick et al. (2006) referiram a ética como a disciplina que se ocupa das questões pertinentes à moral e à moralidade, tratando das formas como os indivíduos agem e reagem. A disciplina de ética estuda os códigos de valores e princípios morais que determinam o comportamento e influencia a tomada de decisões num determinado contexto, em função do que é considerado certo ou errado pela comunidade (ALMEIDA, 2007). Então, ética, ao lado de tradição, costumes, hábitos e leis, e até mesmo para além destas práticas, é um elemento organizador da vida social (ŞAHIN et al., 2009) que, provavelmente, irá variar entre países, ou subgrupos da população.

A percepção de antiética proposta por Shapira-Lishchinsky e Rosenblatt (2008) é a tendência de se comportar mal e, segundo Vardi e Wiener (1996), o mau comportamento é entendido como um ato voluntário de violar normas de organização, principais valores sociais e padrões de conduta adequada. O comportamento antiético desenvolve-se numa organização quando os gestores colocam ênfase apenas na obtenção de resultados econômico-financeiros como o lucro, e punem os trabalhadores quando estes não são atingidos ou as metas não são cumpridas (CHOY, 2012).

\subsection{A liderança ética}

Face aos episódios de falta de ética nos negócios, e em instituições como os governos, organizações sem fins lucrativos e organizações religiosas, as populações passaram a questionar sobre o que está errado com os seus líderes. Os investigadores respondem buscando as origens e resultados da liderança ética nas suas organizações (BROWN; TREVIÑO, 2006). O conundrum está na violação da expectativa de que os líderes sejam honestos, confiáveis, justos, sigam princípios socialmente aceites e se preocupem com as consequências dos seus atos sobre as pessoas e a sociedade em geral (BROWN; TREVIÑO, 2006).

Brown et al. (2005, p. 120) definiram a liderança ética como "a demonstração de conduta normativamente adequada por meio de ações pessoais e relações interpessoais, bem como a promoção de tal conduta para os seguidores, por meio de duas vias de comunicação, de reforço e tomada de decisão". Freeman e Stewart (2006) notaram que para muitos executivos a liderança ética é simplesmente uma questão de ter líderes com bom caráter; com "os valores corretos" e uma "personalidade forte". O líder seria aquele que dá o exemplo e resiste às tentações. Os líderes exibem comportamentos éticos quando fazem o que é moralmente correto, justo e bom, e quando ajudam a elevar a consciência moral dos seguidores e da autorrealização (ZHU; FELLOW; COLLEGE, 2008). Assim, os líderes éticos são fontes de orientação (BROWN; TREVIÑO, 2006) e devem criar as condições adequadas e a cultura organizacional para promover o desenvolvimento moral dos seguidores (ALMEIDA et al., 2008). Zhu et al. (2008) argumentaram que se espera que os líderes éticos tratem os trabalhadores de forma justa e imparcial. 


\subsection{A cultura segundo o Projeto GLOBE}

As definições de 'cultura' são diversas, mas Geert Hofstede (1980) propôs uma conceptualização de cultura como a programação coletiva da mente humana, que distingue os membros de um grupo humano dos de outro grupo, amplamente aceita. Dickson et al. (2012) também concordaram que 'cultura' se refere a um conjunto de elementos que distinguem uma sociedade, ou país, de outrem. Adamson Hoebel, antropólogo, definiu a cultura como "o sistema integrado de padrões de comportamento aprendido, que são característicos dos membros de uma sociedade e que não são o resultado de herança biológica" (ver SALACUSE, 1999). Para Adler (2002) e Dickson et al. (2012), a cultura é o conjunto de valores adotados por um grupo de pessoas que definem o seu modo de vida. Finalmente, Salacuse (1999) definiu cultura como "um conjunto de significados compartilhados e duradouros, valores e crenças que caracterizam um grupo nacional e outros grupos e orienta os seus comportamentos". Assim, os valores culturais traduzem-se em normas, crenças e moral e refletem-se nas leis e práticas da sociedade, incluindo na atuação dos indivíduos no seu meio profissional e das empresas (VENAIK; BREWER, 2010; ALCÂNTARA et al., 2012).

Um conjunto de estudos realizados por House et al. (2004) propôs uma taxonomia de dimensões culturais designada por Projeto GLOBE - Global Leadership and Organizational Behaviour Effectiveness. O projeto GLOBE construiu uma taxonomia composta por nove dimensões culturais para distinguir aspectos específicos das culturas nacionais. Uma diferença importante entre o Projeto GLOBE e as abordagens anteriores, como a de Geert Hofstede $(1980,1991)$ é que cada dimensão cultural é agora investigada em duas manifestações dos valores individuais: as práticas e os valores desejados. As práticas estão relacionadas a perguntas do tipo "O que é?", "O que são?" e aos comportamentos normais, ou seja, às práticas estabelecidas. As dimensões culturais são sucintamente descritas em seguida:

- Distância ao poder: avalia até que ponto os membros de uma coletividade esperam, ou aceitam, que o poder seja distribuído desigualmente. Esta dimensão traduz o nível de aceitação pela sociedade da distribuição desigual do poder dentro das organizações, por meio das relações hierárquicas que se criam entre diretores e subordinados.

- Aversão à incerteza: avalia o grau em que a coletividade se baseia em normas e procedimentos para diminuir os impactos da imprevisibilidade de acontecimentos futuros. Esta dimensão traduz o nível de tolerância das pessoas para a incerteza ou ambiguidade em vários aspectos da sua vida quotidiana, inclusive em situação laboral.

- Orientação humana: o grau em que a sociedade estimula e recompensa as pessoas por serem justas, altruístas, generosas, atenciosas e gentis com as outras.

- Coletivismo institucional: analisa até que ponto as instituições sociais, ou organizações, estimulam os indivíduos a se integrarem em grupos dentro das organizações e da sociedade. $O$ coletivismo conduz as pessoas a valorizarem mais a instituição do que o indivíduo, demonstrando um forte controle sobre o indivíduo por meio de regulamentos internos da instituição.

- Coletivismo do grupo: o grau em que as pessoas se sentem orgulhosas de participar de seus grupos, como a família, círculo de amigos ou a empresa para a qual trabaIham. O coletivismo conduz as pessoas a valorizarem mais o grupo do que o indivíduo, demonstrando um forte controle sobre o indivíduo por meio de regras sociais.

- Agressividade: o grau em que as pessoas são duras, confrontadoras, agressivas e 
competitivas. Esta dimensão demonstra a predominância na sociedade de valores tradicionalmente masculinos, como a assertividade, o materialismo ou a falta de relacionamento com os outros.

- Igualitarismo entre os gêneros: o grau em que a sociedade minimiza as desigualdades entre os gêneros. Realça valores como os relacionamentos interpessoais e a qualidade de vida.

- Orientação para o futuro: o grau em que os indivíduos têm comportamentos orientados ao futuro como o planeamento, investimentos e adiamento de recompensas. Esta dimensão traduz a propensão de determinada sociedade para adotar uma visão de longo prazo no seu desenvolvimento

- Orientação para o desempenho: refere-se à extensão em que a coletividade encoraja e recompensa os indivíduos do grupo por um desempenho superior e por buscar a excelência.

\section{DESENVOLVIMENTO CONCEITUAL E HIPÓTESES}

Neste artigo examinamos como as características culturais influenciam as percepções do que são comportamentos de uma liderança ética. A figura 1 evidencia as relações propostas, que são explicadas em seguida.

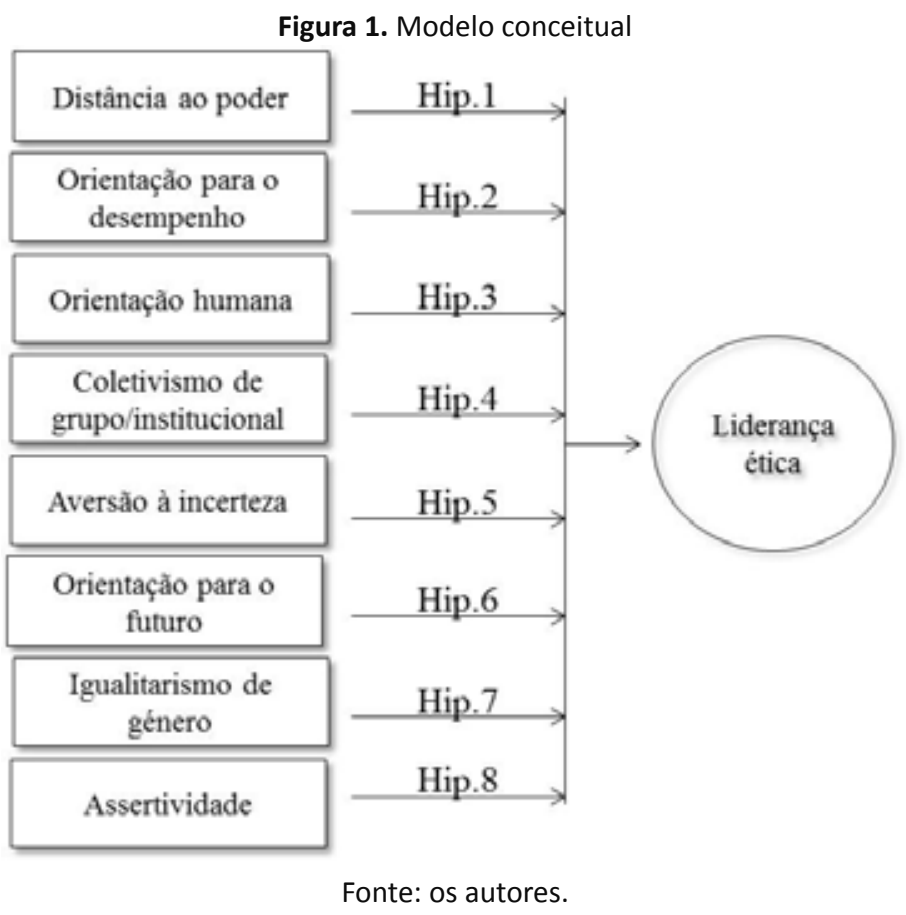

\subsection{Distância ao poder e liderança ética}

Os líderes exibem comportamentos éticos quando fazem o que é moralmente correto, justo e bom, e quando ajudam a elevar a consciência moral e autorrealização dos trabalhadores (ZHU et al., 2008). Então, usando a definição de liderança ética, pode-se razoavelmente pro- 
por que em sociedades de alta distância ao poder os líderes têm maior facilidade em ajudar os seguidores em elevar as suas consciências morais e de auto realização porque estes aceitam a existência de uma hierarquia, denotam elevado respeito pelos seus líderes e implementam as decisões tomadas pelos superiores, mesmo se não estiverem de acordo com eles (HOFSTEDE, 1991; BROWN; TREVIÑO, 2006). Nas sociedades de alta distância ao poder, os trabalhadores esperam que o líder tome as decisões do que deve ser feito e como deve ser feito, sem qualquer consulta aos subordinados. Os códigos de ética, como manifestações de pressupostos básicos da organização, valores fundamentais, normas e crenças, podem ser ferramentas relevantes para o avanço do comportamento ético e desenvolvimento cognitivo (MALLOY; FENNELL, 1998). Segundo Schermerhorn (1989) as organizações devem ajudar os seus trabalhadores a lidar com os dilemas éticos, incluindo reconhecer e esclarecê-los, fim a que os códigos de ética se destinam. Os líderes influenciam no cumprimento dos códigos de ética, e torna-se mais fácil garantir o seu cumprimento nas sociedades com alto nível de distância ao poder, onde os seguidores obedecem aos seus superiores sem questionar as decisões ou formular juízos sobre o que é, ou não, correto.

Hipótese 1: O nível de distância ao poder está positivamente relacionado com a percepção de comportamentos de liderança ética.

\subsection{Orientação para o desempenho e liderança ética}

De acordo com uma das 10 características do líder ético propostas por Freeman e Stewart, (2006), o líder ético concentra-se no sucesso organizacional, em vez do seu interesse pessoal. Nas sociedades altamente orientadas para o desempenho, as pessoas estão focadas nas suas tarefas e buscam da melhor forma possível atingir os objetivos ou as metas, propostos pelo grupo (HOUSE et al., 2004).

A ideia de Freeman e Stewart (2006) de que "Os líderes trabalhando em colaboração com os subordinados podem conseguir a lealdade e também a confiança por parte destes", é reforçada com algumas sugestões fornecidas por Sims (1992), de como as organizações podem encorajar ao comportamento ético. Sims (1992) afirmou que as organizações devem incentivar a participação de todas as pessoas da organização a propósito dos valores e práticas adequadas para a implementação das culturas e também na escolha de valores que representem os pontos de vista dos colaboradores em todos os níveis da organização. Então, podemos propor que em sociedades orientadas para o desempenho, os líderes conseguem obter melhor desempenho porque congregam a colaboração dos trabalhadores, por quem são responsáveis (BROWN; TREVIÑO, 2006). Mittal e Dorfman (2012) reforçam este argumento ao demonstrarem uma correlação positiva entre integridade moral referente a sentimentos como: honestidade, justiça, sinceridade, colaboração, humildade e o valor cultural de orientação para o desempenho. Assim, formula-se a seguinte hipótese:

Hipótese 2: O grau de orientação para o desempenho está positivamente relacionado com a percepção de comportamentos de liderança ética.

\subsection{Orientação humana e liderança ética}

Considerando-se que a ética pode incluir atributos como: o senso de honestidade e justiça, a prudência, o respeito e o serviço pelos outros, além de manter promessas, ser confiável e 
desenvolver relacionamentos de negócios baseados em confiança e integridade (CACIOPPE et al., 2007), parece razoável propor que nas culturas com alto nível de orientação humana os líderes tenderão a apresentar um comportamento mais ético. Esta relação positiva emerge da preocupação com os outros, dando lugar a uma afinidade instintiva entre o valor cultural de orientação humana e o perfil comportamental de um líder ético. A ideia de que existe uma afinidade instintiva entre o valor cultural de orientação humana e o perfil comportamental do líder ético é reforçada com a definição de líder ético sugerida por Brown e Treviño (2006), que afirma que os líderes éticos são vistos como justos e de princípios, são decisores que se preocupam com as pessoas e a sociedade em geral, e que se comportam de forma ética na sua vida pessoal e profissional.

Indivíduos com alto nível de orientação humana tenderão a apresentar um comportamento ético nas suas relações, visto que tendem a serem mais colaborativos, mais propensos a ajudar os outros e, normalmente, não sentirão dificuldades em trabalhar em grupo. Assim, vão ganhando confiança do grupo por serem colaborativos e humildes e também generosos. Esta ideia é fundamentada em algumas das características de um líder ético descritas no trabalho de Freeman e Stewart (2006). Esta argumentação sustenta a seguinte hipótese:

Hipótese 3: O grau de orientação humana está positivamente relacionado com a percepção de comportamentos de liderança ética.

\subsection{Coletivismo de grupo/coletivismo institucional e liderança ética}

Aqui agregamos duas dimensões culturais propostas pelo projeto GLOBE, com sensíveis variações face à dimensão de coletivismo-individualismo do trabalho de Hofstede $(1980,1991)$. Seguindo a racionalidade de que os líderes éticos se preocupam com as pessoas e a sociedade em geral, e que se comportam de forma ética nas suas vidas pessoal e profissional (BROWN; TREVIÑO, 2006), é razoável sugerir que nas sociedades mais coletivistas os líderes tendem a manter as suas relações pessoais pautadas em princípios éticos como humildade, lealdade, colaboração, integridade, porque se sentem confortáveis em fazer parte de um grupo ou de uma instituição (HOUSE et al., 2004). Evidência parcial para esta relação entre coletivismo e liderança ética é encontrada em Mittal e Dorfman (2012), que apuraram uma correlação positiva entre a integridade moral e a dimensão cultural de coletivismo. Relaciona-se, assim, um dos atributos do comportamento ético - a integridade moral - à liderança ética. Na forma de hipótese propõe-se que:

Hipótese 4: O nível de coletivismo do grupo e institucional está positivamente relacionado com a percepção de comportamentos de liderança ética.

\subsection{Aversão à incerteza e à liderança ética}

Nas sociedades de alto índice de aversão à incerteza, os indivíduos tendem a evitar as situações ambíguas, procuram maior estruturação das suas organizações e instituições, e mesmo das relações humanas, de modo a aumentar a previsibilidade (HOFSTEDE, 1991). Os códigos de conduta ética, como um conjunto de princípios gerais e específicos prescritos, fornecem diretrizes para os comportamentos inclusivamente em situações moralmente complexas (FORSYTH; O'BOYLE, 2011), contribuem para reduzir incertezas e aumentar a previsibilidade. Parece, assim, razoável, sugerir que em sociedades de maior aversão à incerteza os líderes cumpram mais os códigos éticos que regem a atuação da organização, agindo de acordo com as regras, normas e 
procedimentos vigentes na organização e na sociedade, tentando evitar situações desconhecidas (HOUSE et al., 2004).

Hipótese 5: O nível de aversão à incerteza está positivamente relacionado com a percepção de comportamentos de liderança ética.

\subsection{Orientação para o futuro e liderança ética}

A orientação para o futuro está, segundo Hofstede (1991), relacionada com as expectativas de tempo do retorno, seja este algum tipo de recompensa ou simplesmente o resultado de uma tarefa ou ação. Propomos que em sociedades com alto nível de orientação para o futuro, o líder tenderá a apresentar comportamentos e ações potencialmente consideradas menos éticas pelos trabalhadores como, por exemplo, adiar uma gratificação (HOUSE et al., 2004). Estes comportamentos são geradores de sentimentos de desonestidade e de desconfiança. Na forma de hipótese:

Hipótese 6: O grau de orientação para o futuro está negativamente relacionado com a percepção de comportamentos de liderança ética.

\subsection{Igualitarismo entre os gêneros e liderança ética}

Igualitarismo entre os gêneros refere-se ao grau em que os membros de uma sociedade minimizam as desigualdades entre os gêneros (HOUSE et al., 2004). A proposta de caracterizar as culturas nacionais com uma mensuração desta dimensão foi avançada por projeto GLOBE, associando à dimensão de feminilidade da taxonomia de Hofstede (1980). Enquanto Hofstede afirmava que nas sociedades feministas os papéis sociais dos gêneros se sobrepõem em algumas facetas (tanto os homens como as mulheres devem ser modestos, ternos e preocupados com a qualidade de vida), também associa a feminilidade a fatores específicos como: hierarquia (ter boas relações de trabalho com a sua chefia direta), cooperação (trabalhar num clima de cooperação), zona onde se vive (viver num meio agradável para si próprio e para a família) e segurança de emprego (ter a segurança de trabalhar na mesma empresa pelo tempo quanto desejarmos).

As funções do líder ético incluem encontrar as melhores pessoas e ajudá-las a desenvolverse, articular e incorporar os objetivos e valores da organização e concentrar-se no sucesso organizacional em vez de no seu interesse pessoal (FREEMAN; STEWART, 2006). De acordo com Mittal e Dorfman (2012), existe uma correlação positiva entre integridade moral (justiça, sinceridade, confiança, colaboração) e valor cultural de igualitarismo de gênero. Pode-se, assim, propor que nas sociedades alto grau de igualitarismo de gênero os líderes tenderão a exibir comportamentos mais éticos.

Hipótese 7: 0 grau de igualitarismo entre os gêneros está positivamente relacionado com a percepção de comportamentos de liderança ética.

\subsection{Assertividade e liderança ética}

A assertividade reflete aspectos como a conflituosidade, agressividade e resistência (HOUSE et al., 2004). A proposta de caracterizar as culturas nacionais com uma mensuração desta dimensão foi avançada por projeto GLOBE, associando à dimensão de masculinidade de Hofstede. Um grau elevado de assertividade indica que predominam na sociedade os valores 
masculinos, como o materialismo ou a falta de relacionamento com os outros. Os valores de masculinidade parecem em contraste com os comportamentos desejados para o líder ético, ao valorizarem o sucesso individual e o progresso em desfavor relativo ao sucesso do conjunto e dos objetivos e valores da organização.

Partindo das definições de assertividade e masculinidade, bem como as características desejáveis para um líder ético, importa entender como a percepção de liderança ética é influenciada pelo valor mais abrangente de assertividade ou masculinidade. Mittal e Dorfman (2012) demonstraram a existência de uma correlação negativa entre a integridade moral (confiança, justiça, honestidade, sinceridade e colaborador) e valor cultural de assertividade, pelo que propomos a seguinte hipótese para teste empírico:

Hipótese 8: O grau de assertividade está negativamente relacionado com a percepção de comportamentos de liderança ética.

\section{MÉTODO}

A seguir descrevem-se os procedimentos metodológicos, sobre a coleta de dados, o instrumento utilizado, variáveis e amostra.

\subsection{Procedimentos de coleta dos dados}

Foi utilizado um questionário composto por 49 itens para medir a variável dependente - liderança ética - e as variáveis independentes assentes em atributos culturais. O questionário completo está disponível mediante solicitação aos autores. Os questionários foram passados em sala de aula com a solicitação de colaboração aos alunos, sem os informar do objetivo do estudo e sem qualquer tipo de recompensa financeira ou crédito escolar pela participação. A participação foi absolutamente facultativa e foi garantida total confidencialidade das respostas, o que foi reforçado chamando a atenção que não havia quaisquer questões que exigissem a identificação do participante e que estes não deviam incluir o seu nome, ou outra forma de identificação, em qualquer das folhas de resposta do questionário. Os questionários foram passados a estudantes de cursos da área de Administração em duas instituições de ensino superior, na Guiné-Bissau (Universidade Colinas do Bué) e em Portugal (Instituto Politécnico de Leiria), em 2013.

\subsection{Variáveis}

A variável dependente é a liderança ética. Esta variável mede o que os participantes pensam ser um líder ético. Para a mensuração utilizamos os 10 itens da escala da liderança ética, desenvolvida por Brown, Treviño e Harrison (2005) (também disponível junto dos autores). Os dez itens foram medidos numa escala tipo Likert de 5 pontos, ancorada em 1-Concordo completamente e 5 - Discordo completamente.

As variáveis independentes compreendem as dimensões culturais do projeto GLOBE (House et al., 2004); distância ao poder, orientação para o desempenho, orientação humana, coletivismo do grupo/institucional, aversão à incerteza, orientação para o futuro, igualitarismo de gênero e assertividade. Estas variáveis e escalas foram utilizadas em trabalhos anteriores como Hofstede (2006) e Dickson et al. (2012). Enquanto no projeto GLOBE os participantes são questionados sobre as práticas culturais, ou seja, "como é" e os valores culturais, como "deve ser", 
este estudo centra somente nas práticas culturais, ou seja, como as coisas são na sociedade dos participantes (Portugal e Guiné-Bissau) e não como desejariam que fossem. As variáveis são brevemente descritas na Tabela 1.

Tabela 1. Descrição das variáveis

\begin{tabular}{|c|c|c|}
\hline \multicolumn{2}{|r|}{ Variável/descrição } & Instrumento \\
\hline \multicolumn{3}{|c|}{ Variável dependente } \\
\hline Liderança ética & $\begin{array}{l}\text { Os líderes exibem comportamentos éticos quando fazem o } \\
\text { que é moralmente correto, justo e bom, e quando ajudam a } \\
\text { elevar a consciência moral dos seguidores e moral da autorre- } \\
\text { alização. Avaliada com os } 10 \text { itens da escala de liderança ética } \\
\text { de Brown, Trevino e Harrison (2005). }\end{array}$ & $\begin{array}{l}\text { Ethical leadership: A } \\
\text { social learning pers- } \\
\text { pective for construct } \\
\text { development and } \\
\text { testing }\end{array}$ \\
\hline \multicolumn{3}{|c|}{ Variáveis independentes } \\
\hline $\begin{array}{l}\text { Distância ao } \\
\text { poder }\end{array}$ & $\begin{array}{l}\text { Refere-se ao grau em que os membros de uma sociedade es- } \\
\text { peram, ou aceitam, que o poder esteja distribuído de forma } \\
\text { desigual. } 5 \text { Itens de House et al. (2004), numa escala tipo Li- } \\
\text { kert de } 7 \text { pontos. }\end{array}$ & $\begin{array}{l}\text { Projeto GLOBE (Hou- } \\
\text { se et al., 2004) } \\
\text { Itens } 5,13,26,27,34\end{array}$ \\
\hline $\begin{array}{c}\text { Orientação para o } \\
\text { desempenho }\end{array}$ & $\begin{array}{l}\text { O grau em que o coletivo encoraja e premia membros dum } \\
\text { grupo pelo aprimoramento e excelência dos seus resultados. } \\
3 \text { itens de House et al. (2004) numa escala Likert de } 7 \text { pontos. } \\
\end{array}$ & $\begin{array}{l}\text { Projeto GLOBE (Hou- } \\
\text { se et al., 2004) } \\
\text { Itens } 18,20,15\end{array}$ \\
\hline $\begin{array}{c}\text { Orientação } \\
\text { humana }\end{array}$ & $\begin{array}{l}\text { O grau em que o coletivo encoraja e premia os indivíduos a } \\
\text { serem justos, altruístas, generosas e gentis uns com os outros. } \\
5 \text { itens de House et al. (2004) numa escala Likert de } 7 \text { pontos. }\end{array}$ & $\begin{array}{l}\text { Projeto GLOBE (Hou- } \\
\text { se et al., 2004) } \\
\text { Itens } 9,21,25,32,33\end{array}$ \\
\hline $\begin{array}{l}\text { Coletivismo de } \\
\text { grupo/ coletivis- } \\
\text { mo institucional }\end{array}$ & $\begin{array}{l}\text { O grau pelo qual os indivíduos expressam lealdade, orgulho } \\
\text { e coesão em suas organizações, famílias e grupos. } 8 \text { itens de } \\
\text { House et al. (2004) numa escala Likert de } 7 \text { pontos. }\end{array}$ & $\begin{array}{l}\text { Projeto GLOBE (Hou- } \\
\text { se et al., 2004) } \\
\text { Itens } 7,11,12,23,28 \text {, } \\
29,35,39\end{array}$ \\
\hline Assertividade & $\begin{array}{l}\text { O grau pelo qual os indivíduos são assertivos, agressivos e } \\
\text { confrontadores. } 4 \text { itens de House et al. (2004) em escala tipo } \\
\text { Likert de } 7 \text { pontos. }\end{array}$ & $\begin{array}{l}\text { Projeto GLOBE (Hou- } \\
\text { se et al., 2004) } \\
\text { Itens } 2,6,10,14\end{array}$ \\
\hline $\begin{array}{l}\text { Igualitarismo do } \\
\text { gênero }\end{array}$ & $\begin{array}{l}\text { O grau em que o coletivo minimiza a desigualdade de gêne- } \\
\text { ro. } 5 \text { items de House et al. (2004) em escala tipo Likert de } 7 \\
\text { pontos. }\end{array}$ & $\begin{array}{l}\text { Projeto GLOBE (House } \\
\text { et al., 2004) } \\
\text { Itens } 17,22,36,37,38\end{array}$ \\
\hline $\begin{array}{l}\text { Orientação para o } \\
\text { futuro }\end{array}$ & $\begin{array}{l}\text { A extensão pela qual os indivíduos estão engajados num com- } \\
\text { portamento orientado para o futuro. } 5 \text { itens de House et al. } \\
\text { (2004), em escala tipo Likert de } 7 \text { pontos. }\end{array}$ & $\begin{array}{l}\text { Projeto GLOBE (Hou- } \\
\text { se et al., 2004) } \\
\text { Itens } 3,4,8,30,31\end{array}$ \\
\hline $\begin{array}{l}\text { Aversão a } \\
\text { incerteza }\end{array}$ & $\begin{array}{l}\text { A extensão em que uma sociedade confia nas normas, regras } \\
\text { e procedimentos como forma de minimizar a imprevisibilida- } \\
\text { de de eventos futuros. } 4 \text { itens de House et al. (2004), em es- } \\
\text { cala tipo Likert de } 7 \text { pontos. }\end{array}$ & $\begin{array}{l}\text { Projeto GLOBE (Hou- } \\
\text { se et al., 2004) } \\
\text { Itens } 1,16,19,24\end{array}$ \\
\hline
\end{tabular}

Por fim, foi incluído um conjunto de variáveis demográficas, como gênero, idade, experiência profissional para caracterizar a amostra. Estudos anteriores mostraram que estas variáveis demográficas podem influenciar comportamentos, e percepções, em matéria de ética (ver, por exemplo, HONEYCUTT et al., 2001; XU, 2009) mas esse não é o objetivo deste estudo.

\subsection{Amostra}

A amostra foi constituída por estudantes universitários dos dois países lusófonos: GuinéBissau e Portugal. Os participantes cursavam Administração. Face ao reduzido número de estudantes na Universidade Colinas de Boé (UCB), na Guiné, a participação estendeu-se a cursos em áreas relacionadas como Administração pública e economia social e de Contabilidade e gestão. Para manter paralelismo na amostra, em Portugal incluem-se estudantes de licenciatura em gestão, con- 
tabilidade e finanças e administração pública. Como expectável, os participantes são relativamente jovens (média de idade próxima dos 24 anos), com sensivelmente a mesma participação de jovens do sexo masculino e feminino, e sem identificarmos diferenças substanciais nos perfis demográficos da amostra portuguesa e guineense, ainda que se note uma participação maior de mulheres em Portugal, o que se tem vindo a tornar uma característica da população universitária.

Tabela 2. Caracterização da amostra

\begin{tabular}{|c|c|c|c|}
\hline & Portugal & Guiné-Bissau & Portugal + Guiné \\
\hline Participantes & 138 & 78 & 216 \\
\hline Cursos & $\begin{array}{l}4 \text { (Gestão, Contabilidade } \\
\text { e finanças, Administração } \\
\text { Publica e Marketing) }\end{array}$ & $\begin{array}{l}2 \text { (Contabilidade e gestão, } \\
\text { Administração Publica e } \\
\text { Economia social) }\end{array}$ & 6 cursos \\
\hline Gênero (M/F) & $49 / 89$ & $51 / 27$ & $100 / 116$ \\
\hline Idade média & 24,62 & 24,4 & 24,36 \\
\hline $\begin{array}{l}\text { Distribuição dos } \\
\text { alunos por ano }\end{array}$ & $\begin{array}{c}1^{\circ} \text { Ano }(40), 2^{\circ} \text { ano }(38) \text { e } \\
3^{\circ} \text { ano (60) }\end{array}$ & $\begin{array}{c}1^{\circ} \text { Ano (27), } 2^{\circ} \text { ano (19), } 3^{\circ} \\
\text { ano (19) e } 4^{\circ} \text { ano (13) }\end{array}$ & $\begin{array}{l}1^{\circ} \text { ano }(67), 2^{\circ} \text { ano }(57), \\
3^{\circ} \text { ano (79) e } 4^{\circ} \text { ano (13) }\end{array}$ \\
\hline $\begin{array}{l}\text { Experiência profis- } \\
\text { sional }\end{array}$ & 86 sim, 52 não & 29 sim, 49 não & 115 sim, 101 não \\
\hline
\end{tabular}

Fonte: Dados da pesquisa.

\subsection{Procedimentos de análise}

As análises estatísticas envolveram testes t para identificação de diferenças nas médias nas variáveis culturais entre os dois países. Em seguida, realizaram-se modelos de equações estruturais simultâneas, com o software PLS, para testar as hipóteses - um para cada país - para entender como as características culturais influenciam as percepções de comportamentos de liderança ética. A não normalidade dos dados da variável dependente inviabiliza o recurso a técnicas alternativas como regressões lineares; sendo um dos requisitos para a utilização de técnicas não paramétricas.

\section{RESULTADOS}

\subsection{Análise comparativa das dimensões culturais entre Portugal e Guiné-Bissau}

Utilizando o software SPSS realizou-se a análise dos testes t para cada dimensão cultural e país, para verificar se existem diferenças significativas nas médias das dimensões culturais entre os dois países. A herança histórica comum, construída sobre laços coloniais até 1974, torna, previsivelmente, mais difícil identificar diferenças culturais significativas entre os países, apesar de estes dois países terem desde então percursos econômicos, sociais e culturais bem diferentes. A imposição de testes estatísticos que assentam na identificação de diferenças culturais e de percepção de liderança ética é, assim, bastante mais exigente. Os resultados, sumariados, na tabela 3, mostram que os países diferem significativamente apenas em quatro dimensões culturais: Orientação para o futuro, Coletivismo de grupo e institucional, Orientação humana e Igualitarismo de gênero. A tabela também mostra as médias para cada dimensão e país. É notório que os portugueses $(M=3,24)$ têm maior orientação para o futuro que os guineenses $(M=2,85)$, maior coletivismo de grupo e institucional $(M=3,16)$ que os guineenses $(M=2,83)$, maior orientação humana $(M=4,54)$ que os guineenses $(M=3,19)$ e maior igualitarismo de gênero $(M=3,58)$ que os guineenses $(M=2,33)$. Nas restantes dimensões culturais não identificamos diferenças significativas. 
Tabela 3. Teste de diferenças culturais médias entre os países

\begin{tabular}{ccccc}
\hline Dimensões culturais & Portugal & Guiné-Bissau & t test (Sig. 2 tailed) \\
\hline Aversão à incerteza & 3,94 & 4,16 & 0,235 \\
Orientação para o futuro & 3,24 & 2,85 & 0,024 & $\checkmark$ \\
Distância ao poder & 3,36 & 3,49 & 0,380 & $\checkmark$ \\
Coletivismo de grupo e institucional & 3,16 & 2,83 & 0,006 & $\checkmark$ \\
Orientação humana & 4,54 & 3,19 & 0,000 & $\checkmark$ \\
Orientação para o desempenho & 3,63 & 3,91 & 0,207 & \\
Igualitarismo de gênero & 3,58 & 2,33 & 0,000 & \\
Assertividade & 3,79 & 3,63 & 0,392 & \\
\hline
\end{tabular}

Fonte: Dados da pesquisa.

\subsection{Teste de hipóteses}

As análises estatísticas basearam-se em dois procedimentos complementares, a validação convergente - para observar quais os itens que contribuem para a formação de cada um dos construtos (variáveis dependentes e independentes) e dos caminhos. Estas análises foram realizadas, separadamente, para cada país, de modo a permitir a comparação entre países. As análises são apresentadas em seguida.

\section{Testes para a Guiné-Bissau}

Primeiro faz-se a análise de validação convergente para determinar quais os itens que contribuem para formação dos construtos respectivos. Nesta etapa, os itens com uma carga (load) inferior a 0.5 entre o item e o constructo (CHIN, 1998) foram retirados, o que conduziu à exclusão de vários itens. Para estabelecer validade convergente também se analisou outras medidas de fit: análise da variância extraída (AVE), confiabilidade composta, $R^{2}$, alfa de Cronbach, comunalidade $e$ redundância. Relativamente a liderança ética verificamos que 5 itens não contribuíam para a formação do constructo, mantendo apenas os restantes itens no modelo. Alguns itens foram eliminados das dimensões culturais tendo-se mantido os seguintes: Coletivismo $(12,23,28,39)$, Aversão à incerteza $(19,24)$, Igualitarismo de gênero $(22,37)$, Orientação para o futuro $(3,4)$, Assertividade $(2$, 14), Distância ao poder (26,27), Orientação para o desempenho (18) e Orientação humana $(9,25)$. Após a eliminação destes itens os indicadores são satisfatórios, como revela a tabela 4. 
Tabela 4. Indicadores gerais do modelo para a Guiné

\begin{tabular}{|c|c|c|c|c|c|c|}
\hline Construtos & AVE & $\begin{array}{l}\text { Confiabilida- } \\
\text { de composta }\end{array}$ & $\mathbf{R 2}$ & Alfa de Cronbach & Comunalidade & Redundância \\
\hline Assertividade & 0,671 & 0,802 & & 0,514 & 0,671 & \\
\hline $\begin{array}{c}\text { Aversão_a_incer- } \\
\text { teza }\end{array}$ & 0,620 & 0,765 & & 0,691 & 0,620 & \\
\hline Coletivismo & 0,477 & 0,728 & & 0,516 & 0,477 & \\
\hline Distância ao poder & 0,619 & 0,764 & & 0,785 & 0,619 & \\
\hline Igualitarismo & 0,572 & 0,715 & & 0,694 & 0,572 & \\
\hline Liderança Etica & 0,401 & 0,820 & 0,434 & 0,750 & 0,401 & 0,042 \\
\hline Orientação Humana & 0,611 & 0,738 & & 0,732 & 0,611 & \\
\hline $\begin{array}{c}\text { Orientação para o } \\
\text { desempenho }\end{array}$ & 1,000 & 1,000 & & 1,000 & 1,000 & \\
\hline $\begin{array}{c}\text { Orientação para o } \\
\text { futuro }\end{array}$ & 0,653 & 0,778 & & 0,617 & 0,653 & \\
\hline
\end{tabular}

Valores de referência Segundo Chin (1998) - AVE, confiabilidade e comunalidade $>0.50$, alfa de Cronbach > 0.60, redundância $<0.50$.

Fonte: Dados da pesquisa.

\section{Análise dos caminhos}

Utilizou-se o PLS para analisar os caminhos. O modelo final com o grau de significância entre os construtos culturais e a percepção de comportamentos de liderança ética é revelado na figura 2. Para analisar a significância das relações utilizou-se a técnica de bootstrapping que envolve a repetição da amostragem dos dados originais para estimar o modelo (HAIR et al., 2005). Neste estudo optou-se por realizar 500 repetições usando 78 casos para verificar o t de student (HAIR et al., 2005). O teste $t$ avalia a significância estatística das diferenças entre duas amostras independentes. Se este valor for suficientemente grande, então, estatisticamente, podemos afirmar que a diferença não se deve a variabilidade da amostra, mas antes que representa reais diferenças. Assim, importa notar que os testes de significância são revelados na figura 2, sendo o caminho significante se o valor de $t$ for superior a 1,96, para os usuais níveis de confiança de $95 \%$. Revela-se que, para a Guiné, há três caminhos positivos significantes de três dimensões culturais para liderança ética: Igualitarismo de gênero, Distância ao poder e Orientação para o desempenho e três caminhos significantes, mas com coeficiente negativo: orientação humana, orientação para o futuro e assertividade. $O R^{2}$ para liderança ética foi alto $(0,43)$.

Tabela 5. Análise dos caminhos para a Guiné

\begin{tabular}{|c|c|c|c|c|c|c|c|c|}
\hline Hip & $\begin{array}{c}\text { Relação } \\
\text { espera- } \\
\text { da }\end{array}$ & Caminho & $\begin{array}{c}\text { Carga } \\
\text { original }\end{array}$ & $\begin{array}{c}\text { Média do } \\
\text { Boots- } \\
\text { trap }\end{array}$ & $\begin{array}{c}\text { Erro Padro- } \\
\text { nizado }\end{array}$ & Test $t$ & Sig & Conclusão \\
\hline $\mathrm{H} 1$ & + & $\begin{array}{c}\text { Distância ao po- } \\
\text { der à Liderança } \\
\text { ética }\end{array}$ & 0,311 & 0,296 & 0,103 & 3,009 & $p<0,01$ & suportada \\
\hline $\mathrm{H} 2$ & + & $\begin{array}{l}\text { Orientação para } \\
\text { o desempenho à } \\
\text { Liderança ética }\end{array}$ & 0,265 & 0,243 & 0,101 & 2,618 & $p<0,01$ & suportada \\
\hline H3 & + & $\begin{array}{l}\text { Orientação hu- } \\
\text { mana à Liderança } \\
\text { ética }\end{array}$ & $-0,254$ & $-0,264$ & 0,123 & 2,066 & $p<0,05$ & $\begin{array}{l}\text { não supor- } \\
\text { tada }\end{array}$ \\
\hline
\end{tabular}




\begin{tabular}{|c|c|c|c|c|c|c|c|c|}
\hline $\mathrm{H} 4$ & + & $\begin{array}{l}\text { Coletivismo à Li- } \\
\text { derança ética }\end{array}$ & $-0,110$ & $-0,125$ & 0,080 & 1,371 & n.s. & $\begin{array}{l}\text { não supor } \\
\text { tada }\end{array}$ \\
\hline $\mathrm{H} 5$ & + & $\begin{array}{l}\text { Aversão incerteza } \\
\text { à Liderança ética }\end{array}$ & 0,041 & 0,110 & 0,081 & 0,512 & n.s. & $\begin{array}{l}\text { não supor- } \\
\text { tada }\end{array}$ \\
\hline $\mathrm{H} 6$ & - & $\begin{array}{l}\text { Orientação para o } \\
\text { futuro à Liderança } \\
\text { ética }\end{array}$ & $-0,267$ & $-0,257$ & 0,114 & 2,354 & $p<0,05$ & suportada \\
\hline $\mathrm{H} 7$ & + & $\begin{array}{l}\text { Igualitarismo à } \\
\text { Liderança ética }\end{array}$ & 0,238 & 0,226 & 0,099 & 2,407 & $p<0,05$ & suportada \\
\hline $\mathrm{H} 8$ & - & $\begin{array}{l}\text { Assertividade à } \\
\text { Liderança ética }\end{array}$ & $-0,384$ & $-0,376$ & 0,101 & 3,806 & $p<0,01$ & suportada \\
\hline
\end{tabular}

Nota; valores críticos para $\mathrm{t}(499)=1,96=p<0,05 ; 2,58=p<0,01$.

Fonte: Dados da pesquisa.

\section{Testes para Portugal}

Os dados com os participantes portugueses são sujeitos aos mesmos procedimentos descritos anteriormente. Neste estudo optou-se por realizar 500 repetições usando 138 casos para verificar o t de student. Primeiro fazemos uma análise de validação convergente para identificar quais os itens que contribuem para formação de cada um dos constructos. Excluímos os itens cuja carga no respectivo construto seja inferior a 0,5, tendo sido retidos os seguintes itens: Coletivismo $(23,29,39)$, Aversão à incerteza $(16,24)$, Igualitarismo de gênero $(17,22)$, Orientação para o futuro (30,31), Assertividade $(2,6)$, Distância ao poder $(26,27,34)$, Orientação para o desempenho e Orientação humana (todos os itens retidos). Como mostra a tabela 6 os indicadores são adequados. $O R^{2}$ para liderança ética foi de 0,23 .

Tabela 6. Indicadores gerais do modelo para Portugal

\begin{tabular}{|c|c|c|c|c|c|c|}
\hline Construtos & AVE & $\begin{array}{l}\text { Confiabilida- } \\
\text { de composta }\end{array}$ & $\mathbf{R}^{2}$ & $\begin{array}{c}\text { Alfa de } \\
\text { Cronbach }\end{array}$ & Comunalidade & Redundância \\
\hline Assertividade & 0,603 & 0,002 & & 0,519 & 0,603 & \\
\hline Aversão a incerteza & 0,466 & 0,015 & & 0,730 & 0,466 & \\
\hline $\begin{array}{l}\text { Coletivismo grupo/ } \\
\text { institucional }\end{array}$ & 0,377 & 0,643 & & 0,679 & 0,377 & \\
\hline Distância ao Poder & 0,588 & 0,809 & & 0,664 & 0,588 & \\
\hline $\begin{array}{l}\text { Igualitarismo de } \\
\text { gênero }\end{array}$ & 0,495 & 0,074 & & 0,822 & 0,495 & \\
\hline Liderança ética & 0,664 & 0,952 & 0,232 & 0,943 & 0,664 & 0,019 \\
\hline Orientação humana & 0,424 & 0,784 & & 0,742 & 0,424 & \\
\hline $\begin{array}{l}\text { Orientação para o } \\
\text { desempenho }\end{array}$ & 0,457 & 0,715 & & 0,624 & 0,457 & \\
\hline $\begin{array}{l}\text { Orientação para o } \\
\text { futuro }\end{array}$ & 0,743 & 0,852 & & 0,660 & 0,743 & \\
\hline
\end{tabular}

Valores de referência Segundo Chin (1998) - AVE, confiabilidade e comunalidade $>0,50$, alfa de Cronbach $>0.60$, redundância $<0,50$.

Fonte: Dados da pesquisa.

A Tabela 7 mostra a significância dos caminhos. Três dimensões culturais - Distância ao poder, Orientação para o desempenho e Aversão à incerteza têm um caminho positivo e significante, enquanto Assertividade tem um caminho significante, mas negativo, como proposto. 
Tabela 7 Análise dos caminhos para Portugal

\begin{tabular}{|c|c|c|c|c|c|c|c|c|}
\hline Hip & $\begin{array}{l}\text { Relação } \\
\text { espera- } \\
\text { da }\end{array}$ & Caminho & $\begin{array}{l}\text { Carga } \\
\text { original }\end{array}$ & $\begin{array}{l}\text { Média do } \\
\text { Boots- } \\
\text { trap }\end{array}$ & $\begin{array}{l}\text { Erro } \\
\text { Padroni- } \\
\text { zado }\end{array}$ & Test $t$ & Sig & Conclusão \\
\hline $\mathrm{H} 1$ & + & $\begin{array}{l}\text { Distância ao poder à } \\
\text { Liderança ética }\end{array}$ & 0,190 & 0,181 & 0,082 & 2,352 & $p<0,05$ & suportada \\
\hline $\mathrm{H} 2$ & + & $\begin{array}{c}\text { Orientação para o de- } \\
\text { sempenho à Liderança } \\
\text { ética }\end{array}$ & 0,146 & 0,167 & 0,081 & 1,985 & $p<0,05$ & suportada \\
\hline H3 & + & $\begin{array}{c}\text { Orientação humana à } \\
\text { Liderança ética }\end{array}$ & $-0,090$ & $-0,129$ & 0,124 & 0,971 & n.s. & $\begin{array}{l}\text { não supor- } \\
\text { tada }\end{array}$ \\
\hline $\mathrm{H} 4$ & + & $\begin{array}{l}\text { Coletivismo à Lideran- } \\
\text { ça ética }\end{array}$ & 0,144 & 0,170 & 0,098 & 1,528 & n.s. & $\begin{array}{l}\text { não supor- } \\
\text { tada }\end{array}$ \\
\hline $\mathrm{H} 5$ & + & $\begin{array}{l}\text { Aversão incerteza à } \\
\text { Liderança ética }\end{array}$ & 0,167 & 0,037 & 0,183 & 2,146 & $p<0,05$ & suportada \\
\hline $\mathrm{H} 6$ & - & $\begin{array}{l}\text { Orientação para o fu- } \\
\text { turo à Liderança ética }\end{array}$ & $-0,039$ & $-0,047$ & 0,079 & 0,722 & n.s. & $\begin{array}{l}\text { não supor- } \\
\text { tada }\end{array}$ \\
\hline $\mathrm{H} 7$ & + & $\begin{array}{l}\text { Igualitarismo à Lide- } \\
\text { rança ética }\end{array}$ & $-0,097$ & $-0,057$ & 0,123 & 1,401 & n.s. & $\begin{array}{l}\text { não supor- } \\
\text { tada }\end{array}$ \\
\hline $\mathrm{H} 8$ & - & $\begin{array}{l}\text { Assertividade à Lide- } \\
\text { rança ética }\end{array}$ & $-0,173$ & $-0,033$ & 0,198 & 2,161 & $p<0,05$ & suportada \\
\hline
\end{tabular}

Nota; valores críticos para $\mathrm{t}(499)=1,96=p<0,05 ; 2,58=p<0,01$.

Fonte: Dados da pesquisa.

Pode-se, então analisar as hipóteses, mas diferenciando entre os países. A análise dos dados e resultados referentes à Guiné-Bissau permite concluir que nem todas as hipóteses foram suportadas. Apenas se encontrou sustentação para as hipóteses 1, 2, 6, 7 e 8. Para as hipóteses restantes não se identificou, nesta amostra, uma relação estatisticamente significativa.

No que concerne aos dados e resultados para Portugal, verificou-se que as hipóteses 1 , 2, 5 e 8 foram suportadas, uma vez que todas elas apresentam um nível de significância de t superior a 1,96. Não se encontrou evidência estatística que permita sustentar as restantes hipóteses.

\section{DISCUSSÃO}

Neste estudo procurou-se estabelecer como as características culturais nacionais poderiam influenciar as percepções do que são comportamentos de liderança ética. Esta questão é especialmente relevante num mundo contemporâneo em que muitas empresas se internacionalizam (SCHERER, 2012) e precisam entender não apenas como as culturas variam entre países, mas também como podem influenciar as operações das empresas. As questões relativas à gestão das subsidiárias no estrangeiro, onde se enquadram os modelos de gestão e de interação com os trabalhadores, proporcionam o contexto conceitual em que se enquadra este trabalho. Assim, o desenvolvimento conceitual deste artigo está assente num conjunto de hipóteses relacionando diferentes facetas culturais com a liderança ética para entender, em primeira instância como melhor gerir as subsidiárias no estrangeiro em matéria de liderança ética. $O$ estudo permite concluir que cada país (ou cultura nacional) tem uma percepção idiossincrática do que entende por liderança ética, porque cada sociedade tem seus usos, costumes, tradições e valores que influenciam a percepção do que é (ser) ético.

Este estudo é relevante por três motivos adicionais. É o primeiro estudo a utilizar simultaneamente a junção destes dois conceitos, mensurados desta forma. Segundo, inclui dois países - Portugal e Guiné-Bissau - que não são usualmente contemplados na pesquisa internacional, 
permanecendo largamente desconhecidas questões culturais pertinentes para os gestores e empresas multinacionais. Terceiro, ao utilizar o projeto GLOBE utiliza uma extensa tipologia de dimensões culturais que não seria possível usando-se taxonomias alternativas, como a tipologia de Hofstede, e, assim, obtendo maior detalhe.

As análises relativas à Guiné-Bissau indicam que a liderança ética foi formada por 5 itens, o que nos permite caracterizar as percepções dos guineenses, segundo os quais a liderança ética compreende um líder confiável, de decisões justas que disciplina os funcionários que violam as normas éticas, e que insere os seus trabalhadores nas discussões de dilemas éticos facilitando assim a obtenção dos resultados com respeito as normas de conduta ética. Este resultado contraria, em parte, o resultado encontrado por Brown, Treviño e Harrison (2005), que afirma que os dez itens formam um constructo coerente da liderança ética, mas tem o benefício de podermos entender o construto fora do domínio geográfico para o qual foi desenvolvido. Também os ajustamentos aos construtos culturais são pertinentes na medida em que confirmam as suspeitas que não há uma universalidade na forma como os cidadãos de diferentes países integram os atributos culturais. De salientar a este respeito que apenas 17 dos 39 itens de House et al. (2004) foram retidos. Os resultados indicam ainda que somente as quatro hipóteses foram confirmadas, ainda que com uma capacidade explicativa bastante significativa.

Os resultados para Portugal mostram diferenças substanciais. Primeiro, é notável como o construto de liderança ética reteve todos os itens, em contraste com o caso guineense, o que revela que apesar da herança histórica e colonial que une Portugal e a Guiné-Bissau, os países desenvolveram desde 1974 percursos marcadamente distintos e hoje Portugal é um país ocidental de desenvolvimento intermédio que partilha traços culturais fortes com os parceiros europeus. Os dados validam, assim, a escala de liderança ética proposta por Brown, Treviño e Harrison (2005). Situação distinta encontra-se para a formação dos construtos culturais em que 17 itens do instrumento original não contribuem para formar os construtos.

No teste das hipóteses evidenciam-se diferenças importantes entre os dois países. Além das leituras e interpretações individualizadas que se podem fazer, é interessante notar como a capacidade explicativa do impacto dos construtos culturais é muito superior na Guiné-Bissau $\left(R^{2}=0,43\right)$ que em Portugal $\left(R^{2}=0,23\right)$. Assim, em face aos escândalos de liderança ética corporativa que têm matizado o mundo ocidental, importa entender que outros fatores poderão fundamentar as percepções do que é liderança ética. É possível que outros fatores institucionais legais, políticos e econômicos também sejam relevantes. Este é espaço para ser explorado em pesquisas futuras.

\subsection{Limitações e pesquisa futura}

Este estudo tem um conjunto de limitações que importa notar. Algumas limitações são inerentes à dificuldade de obter uma amostra maior, em especial na Guiné-Bissau. Para manter maior convergência na amostra limitámos a pesquisa a estudantes de cursos na área da Administração, mas pesquisas futuras podem verificar eventuais diferenças para outras formações acadêmicas. $O$ mais surpreendente foi a relativa dificuldade que os participantes guineenses tiveram em saber responder ao instrumento de pesquisa, pela falta de hábito de participar em pesquisas acadêmicas.

Uma dificuldade expectável esteve em identificar outros estudos envolvendo estes dois países que nos servissem de referência para estabelecer uma ligação conceitual entre os constructos culturais e a liderança ética. Esta dificuldade majorada quando se analisa países que embora em continentes distintos e com nível de desenvolvimento econômico, social e institucional severamente desigual têm uma herança histórica que os une. Estudos futuros conseguirão ul- 
trapassar estas dificuldades com maior diversidade de países. Futuras pesquisas podem, ainda, expandir para países que têm tido forte atenção do público, poder político e empresários e gestores, como é o caso dos países de economias emergentes. Estes países têm atraído fortes fluxos de investimento estrangeiro e têm assistido à localização de muitas empresas multinacionais que precisam aprender a operar localmente. A legitimidade local destas empresas estrangeiras passa, certamente, pela adoção de inúmeras normas e procedimentos, e que provavelmente se incluem os aspectos relativos à adoção e comportamentos de liderança ética. Assim, entender o que a população entende por comportamentos éticos é manifestamente relevante.

Por fim, a utilização de estudantes como amostra para o estudo é uma limitação bem conhecida dos pesquisadores. Se por um lado, os atuais estudantes serão os profissionais de amanhã e podemos prever os seus comportamentos futuros, face ao seu sistema de valores atual, também é realidade que não têm a vivência profissional que lhes permita efetivamente avaliar algumas das questões que lhes foram colocadas. Esta limitação pode ser ultrapassada em estudos futuros alargando a amostra aos profissionais em diversos setores de atividade e a operar em diversos níveis da organização. Estes estudos poderão confirmar alguma universalidade, ou capacidade de generalização, dos resultados.

\section{COMENTÁRIOS FINAIS}

A cultura exerce uma influência significativa sobre a ética, as normas, valores e comportamentos éticos, mas essa influência não é homogênea como denotam os nossos resultados. Para as empresas é relevante entender como as dimensões culturais atuais e que outras dimensões ou fatores impactam na ética empresarial, visto que a valorização de práticas éticas pode ser uma fonte de vantagem (HUHTALA et al., 2012). A liderança ética pode ainda ser uma vantagem para atrair e reter os melhores e mais qualificados colaboradores, além de contribuir para a meIhor adaptação aos locais receptores. Pesquisa adicional é necessária para aprofundar o nosso entendimento não apenas do impacto da cultura nacional na adopção de comportamentos mais ou menos éticos, mas, também, em sobre todos os outros fatores institucionais que sendo específicos aos países e seus povos permitem entender os modelos de atuação e organização que garantam legitimidade local.

\section{REFERÊNCIAS}

ADLER, N. International dimensions of organizational behavior. $4^{\text {th }}$ ed., Cincinatti, OH: South-Western College Publishing, 2002.

ALCÂNTARA, V.; REIS, P.; MENEZES, R. Identificação de clusters internacionais com base nas dimensões culturais de Hofstede. Revista de Administração da UFSM, v. 5, n. 2, p. 204-221, 2012.

ALMEIDA, J. Ética e desempenho social das organizações: Um modelo teórico de análise dos fatores culturais e contextuais. Revista de Administração Contemporânea, v. 11, n. 3, p.
105-125, 2007.

ALMEIDA, M.; NOVAES, M.; YAMAGUTI, C. Liderança e gestão estratégica de pessoas: Duas faces da mesma moeda. Revista de Administração da UFSM, v. 1, n. 1, p. 7-25, 2008.

AVEY, J.; WEMSING, T.; PALANSKI, M. Exploring the process of ethical leadership: The mediating role of employee voice and psychological ownership. Journal of Business Ethics, v. 107 n. 1, p. 21-34, 2012.

BONDARICK, R.; PILATTI, A.; FRANCISCO, C. Ética managerial: A ética nas organizações empresárias. Journal of Technology 
Management e Innovation, v. 1, n. 5, p. 69-75, 2006.

BROWN, M.; TREVIÑO, L. Ethical leadership: A review and future directions. The Leadership Quarterly, v. 17, n. 6, p. 595-616, 2006.

BROWN, M.; TREVIÑO, L.; HARRISON, D. Ethical leadership: A social learning perspective for construct development and testing. Organizational Behavior and Human Decision Processes, v. 97 n. 2, p. 117-134, 2005.

CACIOPPE, R.; FORSTER, N.; FOX, M. A survey of managers' perceptions of corporate ethics and social responsibility and actions that may affect companies' success. Journal of Business Ethics, v. 82, n. 3, p. 681-700, 2007.

CHIN, W. The partial least squares approach for structural equation modeling. In Marcoulides, G. (Ed.), Moderns Methods for Business Research: Methodology for Business and Management. Mahwah, NJ, US: Lawrence Erlbaum Associates Publishers, p. 295-336, 1998.

CHOY, D. How consumers perceive the ethical conduct of businesses and their managers. International Management Review, v. 8, n. 1, p. 44-49, 2012.

DICKSON, M.; CASTAÑO, N.; MAGOMAEVA, A.; DEN HARTOG, D. Conceptualizing leadership across cultures. Journal of World Business, v. 47, n. 4, p. 483-492, 2012.

FORSYTH, D.; O'BOYLE, E. Rules, standards, and ethics: Relativism predicts cross-national differences in the codification of moral standards. International Business Review, v. 20, n. 3, p. 353-361, 2011.

FREEMAN, R.; STEWART, L. Developing ethical leadership. Institute for Corporate Ethics, 2006.

GEERTZ, C. A interpretação das culturas. Rio de Janeiro, RJ: Livros Técnicos e Científicos, 1989.
HAIR, J.; ANDERSON, R.; TATHAM, R.; BLACK, W. Análise multivariada de dados, Porto Alegre, RS: Bookman, 2005.

HOFSTEDE, G. Culture's consequences: International differences in work-related values. Beverly Hills, CA: Sage, 1980.

HOFSTEDE, G. Cultura e organizações: Compreender a nossa programação mental. Lisboa: Silabo, 1991.

HOFSTEDE, G. Culture's consequences: Comparing values, behaviors, institutions, and organizations across nations, $2^{\mathrm{a}}$ ed, Thousand Oaks, CA: Sage, 2001.

HOFSTEDE, G. What did GLOBE really measure? Researchers' minds versus respondents' minds. Journal of International Business Studies, v. 37, n. 6, p. 882-896, 2006.

HOFSTEDE, G. The GLOBE debate: Back to relevance. Journal of International Business Studies, v. 41, p. 1339-1346, 2010.

HOFSTEDE, G.; HOFSTEDE, G.; MINKOV, $M$. Cultures and organizations: Software of the mind, 3a ed., New York, NY: McGraw-Hill, 2010.

HONEYCUTT, E.; GLASSMAN, M.; ZUGEELDER, M.; KARANDE, K. Determinants of ethical behavior: A study of auto sale-people. Journal of Business Ethics, v. 32, p. 69-79, 2001.

HOUSE, R.; HANGES, P.; JAVIDAN, M.; DORFMAN, P.; GUPTA, V. Culture, leadership and organizations: The GLOBE study of $\mathbf{6 2}$ societies. Thousand Oaks, CA: Sage Pub., 2004.

HUHTALA, M.; FELDT, T.; HYVÖNEN, K.; MAUNO, $S$. Ethical organizational culture as a context for managers' personal work goals. Journal of Business Ethics, v. 144, n. 2, p. 265-282, 2012.

LAU, L.; CARACCIOLO, B.; SCROGGINGS, A. College students' perception of ethics. Journal of Academic and Business Ethics, v. 5, p. 1-13, 2012. 
LEWIS, P. Defining business ethics: Like nailing jello to a wall. Journal of Business Ethics, v. 4, n. 8, p. 377-383, 1985.

MALLOY, D.; FENNELL, D. Codes of ethics and tourism: An exploratory content analysis. Tourism Management, v. 19, n. 5, p. 453-461, 1998.

MITTAL, R.; DORFMAN, P. Servant leadership across cultures. Journal of World Business, v. 47, n. 4, p. 555-570, 2012.

NEJATI, M.; AMRAN, A.; SHAHBUDIN, A. Attitudes towards business ethics: Acrosscultural comparison of students in Iran and Malaysia. Journal of Business Governance and Ethics, v. 6, n.1, p. 68-82, 2011.

PHAU, I.; KEA, G. Attitudes of university students toward business ethics: A crossnational investigation of Australia, Singapore and Hong Kong. Journal of Business Ethics, $v$. 72, n. 1, p. 61-75, 2007.

ŞAHIN, R.: ÖZTÜRK.; ÜNALMIŞ, M. Professional ethics and moral values in Akhi institution. Procedia: Social and Behavioral Sciences, v. 1, n. 1, p. 800-804, 2009.

SALACUSE, J. Intercultural negotiation in international business. Kluwer Academic Publishers, p. 217-236, 1999.

SANTOS, E. Responsabilidade social ou filantropia? Sanare. Revista Técnica da Sanepar, v. 20, p. 18-27, 2003.

SCHERER, F. Como empresas consolidam a presença em mercados estrangeiros? Considerações sobre o processo de internacionalização. Revista de Administração da UFSM, v.5, n. 3, p. 1-20, 2012.

SCHERMERHORN, J. Management for productivity. $3^{\circ}$ ed. New York, NY: Wiley, 1989.

SHAPIRA-LISHCHINSKY, O.; ROSENBLATT, Z. Perceptions of organizational ethics as predictors of work Absence: A test of alternative absence measures. Journal of Business Ethics, v. 88, n. 4, p. 717-734, 2008.

SIMS, R. The challenge of ethical behavior in organizations. Journal of Business Ethics, v. 11, p. 505-513, 1992

TYLOR, E. Primitive culture: researches into the development of mythology, philosophy, religion, art, and custom. London: John Murray, 1871.

VARDI, Y.; WIENER, Y. Misbehavior in organizations: A motivational Framework. Organizational Science, v. 7, n. 2, p. 151-165, 1996.

VENAIK, S.; BREWER, P. Avoiding uncertainty in Hofstede and GLOBE. Journal of International Business Studies, v. 41 , n. 8 , p. $1294-1315$, 2010.

VICTOR, B.; CULLEN, J. The organizational bases of ethical work climates. Administrative Science Quarterly, v. 33, p. 101-125, 1988.

WALUMBWA, F.; SCHAUBROECK, J. Leader personality and employee voice behavior: Mediating roles of ethical leadership and work group psychological safety. Journal of Applied Psychology, v. 94, p. 1275-1286, 2009.

$\mathrm{XU}, \mathrm{X}$. The conceptualization and effectiveness of ethical leadership. Tese de doutorado não publicada, University of Chinese Academy of Sciences, 2009.

ZHU, B.; FELLOW, P.; COLLEGE, C. The effect of ethical leadership on follower moral identity: The mediating role of psychological empowerment. Leadership Review, v. 8, p. 6273, 2008. 